\title{
Understanding Preclerkship Medical Students' Poor Performance in Prescription Writing
}

"Henry James, Khalid A. J. Al Khaja, Yasin I. Tayem, Sindhan Veeramuthu, Reginald P. Sequeira

$$
\begin{aligned}
& \text { فهم أداء طلاب الطب في المرحلة ما قبل الدراسة السريرية } \\
& \text { ضعف الأداء في كتابة الوصفات الطبية }
\end{aligned}
$$

هنري جيمس، خالد أحمد جاسم الخاجة، ياسين إبراهيم تيم، سندان فيراموثو، ريجنالد سكويرا

ABSTRACT: Objectives: This study aimed to explore reasons for poor performance in prescription writing stations of the objective structured practical examination (OSPE) and absenteeism in prescription writing sessions among preclerkship medical students at the Arabian Gulf University (AGU) in Manama, Bahrain. Methods: This descriptive study was carried out between September 2014 and June 2015 among 157 preclerkship medical students at AGU. Data were collected using focus group discussions and a questionnaire with closed-and open-ended items. Results: All 157 students participated in the study (response rate: 100.0\%). The most frequently cited reasons for poor performance in OSPE stations were an inability to select the correct drugs (79.6\%), treatment duration (69.4\%), drug quantity (69.4\%) and drug formulation (68.2\%). Additionally, students reported inadequate time for completing the stations (68.8\%). During focus group discussions, students reported other reasons for poor performance, including examination stress and the difficulty of the stations. Absenteeism was attributed to the length of each session (55.4\%), lack of interest (50.3\%), reliance on peers for information (48.4\%) and optional attendance policies (47.1\%). Repetitive material, large group sessions, unmet student expectations and the proximity of the sessions to summative examinations were also indicated to contribute to absenteeism according to open-ended responses or focus group discussions. Conclusion: This study suggests that AGU medical students perform poorly in prescription writing OSPE stations because of inadequate clinical pharmacology knowledge. Participation in prescription writing sessions needs to be enhanced by addressing the concerns identified in this study. Strategies to improve attendance and performance should take into account the learner-teacher relationship.

Keywords: Medical Students; Medical Education; Drug Prescriptions; Inappropriate Prescribing; Absenteeism; Formularies; Bahrain.

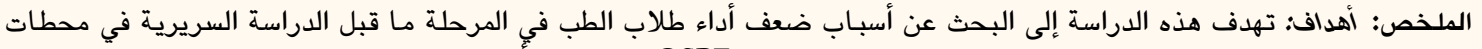

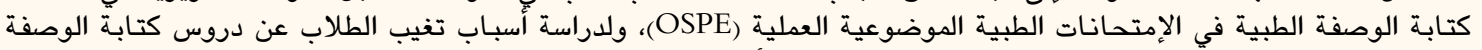

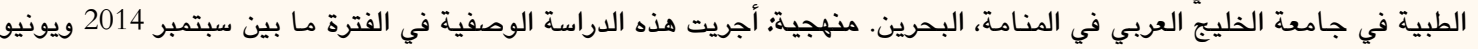

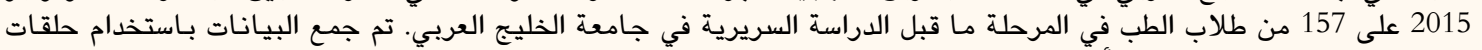

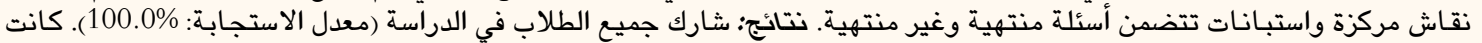

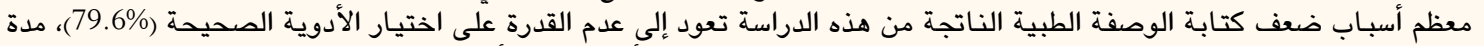

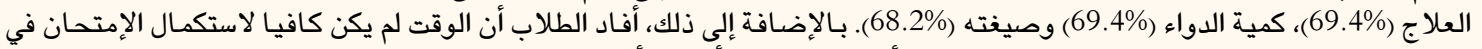

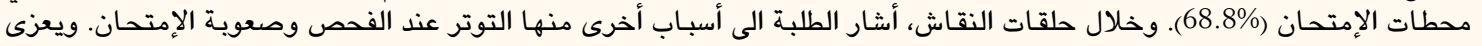

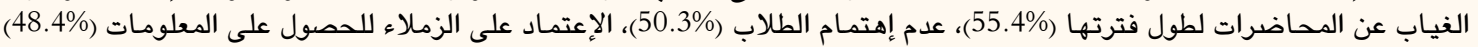

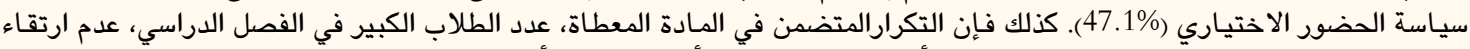

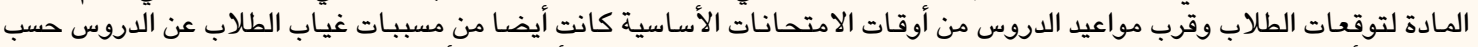

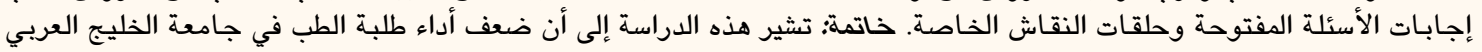

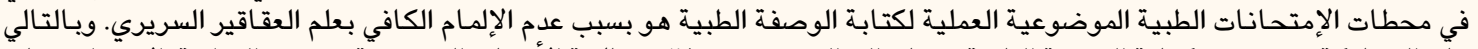

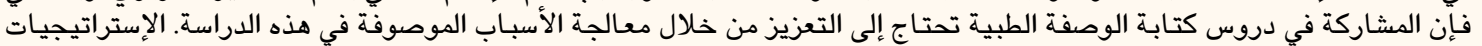

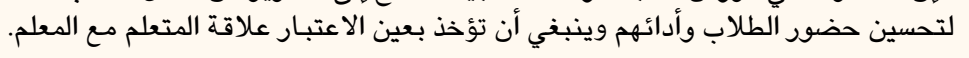

كلمات مفتاحية؛ طلاب الطب؛ التعليم الطبي؛ وصفات الأدوية؛ وصف الأدوية الغيرمناسب؛ الغياب؛ معجم الأدوية؛ البحرين.

\section{Advances In KNOWLEDGe}

This study sheds light on reasons for poor performance in drug-related components of prescription writing and absenteeism in prescription writing sessions among medical students at a university in Bahrain. This information is important to make any necessary changes in the medical curriculum so as to improve student participation, training and performance as rational drug prescribers. 


\section{Application to Patient Care}

Irrational drug prescribing and prescribing errors are common and complicate patient care by causing preventable suffering. This study may help to minimise these problems by enhancing the training of medical students in rational drug prescribing.

$\mathrm{R}$ ATIONAL DRUG PRESCRIBING IS ONE OF the most important competencies of health prescriptions. $^{1,2}$ However, prescriptions written by qualified health professionals and medical students are sometimes irrational and contain various errors. ${ }^{3-5}$ It has been suggested that medical schools do not adequately train students in prescribing drugs and this can compromise patient safety. ${ }^{6,7}$ A typical drug prescription has standard components which fall into three categories: patient-related (name, age and gender), physician-related (identity of the prescriber) and drug-related (drug name, dose, formulation, route and frequency of administration, quantity to be dispensed, duration of treatment and directions for use). ${ }^{8}$

The College of Medicine \& Medical Sciences at the Arabian Gulf University (AGU) in Manama, Bahrain, offers a six-year degree programme divided into three phases: phase I (premedical), phase II (preclerkship) and phase III (clerkship). ${ }^{9}$ There is a dedicated programme for teaching prescription writing to students within the nine-unit preclerkship phase; typically, at the end of a unit or subunit, a dedicated 1.5-2-hour interactive prescription writing session is conducted relating to the topics addressed in the unit. Such programmes have been found to enhance rational prescribing skills among medical students. ${ }^{10}$ During prescription writing sessions, students are trained in medication prescribing and learn about the various components of a prescription and chart order. At the beginning of each session, a general introduction is given about rational therapeutic decision-making processes and the prescription format. This is followed by discussion of 5-6 clinical case scenarios with emphasis resting on why a particular drug is prescribed or not prescribed. To foster this understanding, theoretical aspects are discussed which necessitate the repetition of concepts the students have studied in the previous weeks of that unit. The rational therapeutic decision-making process and the prescription format are also repeated in every unit. At AGU, students are taught self-regulated learning and are provided with the British National Formulary (BNF) as a reference for relevant prescribing information. ${ }^{11}$

At the end of each unit, students' prescription writing skills are tested at the pharmacotherapy stations of an objective structured practical examination (OSPE). This examination is followed by a review session where model answers are discussed; students are then given feedback on their examination results and advice on how to improve their performance. An earlier study indicated that preclerkship students at AGU perform particularly poorly in the drug-related components of a prescription. ${ }^{5}$ Moreover, another study from AGU found a positive correlation between students' attendance at prescription writing classes and their examination performance, with students who had attended the two-hour interactive prescription writing sessions performing better in the summative examinations than the absentees. ${ }^{12}$

At AGU, the medical programme is continuously evaluated with regards to examination performance based on staff and student feedback so that necessary changes in the curriculum can be made to improve AGU students' participation, learning and performance. The present study aimed to identify the reasons for students' poor performance in the drugrelated components of prescription writing, as well as the high rates of absenteeism in prescription writing sessions.

\section{Methods}

This descriptive study was carried out at AGU in the academic year September 2014 to June 2015 and included 157 third- and fourth-year medical students. Second-year medical students were not included in the study because of their limited exposure to prescription writing sessions and the OSPEs. As the study was focused on phase II preclerkship students, first-year students (premedical, phase I) and fifth- and sixth-year students (clerkship, phase III) were also not included.

A 24-item English-language questionnaire was designed to collect information from the students, with 12 questions exploring reasons for poor performance in the drug-related components of prescription writing in the OSPE and the remaining 12 items focusing on reasons for absenteeism from interactive prescription writing sessions. All questions were closed-ended (yes/no) although sections were provided for openended responses. The key knowledge and skill competencies required for writing a prescription were taken into account when preparing all questionnaire items. The questionnaire was tested on a pilot group of 10 fourth-year students who later participated 
Table 1: Reasons for poor performance in prescription writing components of the objective structured practical examination according to preclerkship students at the Arabian Gulf University, Manama, Bahrain $(\mathrm{N}=157)$

\begin{tabular}{|c|c|}
\hline Reasons & n (\%) \\
\hline \multicolumn{2}{|l|}{ Closed-ended responses } \\
\hline Difficulty in selecting a particular drug(s) & $125(79.6)$ \\
\hline Inability to decide on duration of treatment & 109 (69.4) \\
\hline $\begin{array}{l}\text { Inability to decide on quantity of drug to be } \\
\text { dispensed }\end{array}$ & $109(69.4)$ \\
\hline Lack of time & $108(68.8)$ \\
\hline Inability to decide on drug formulation & $107(68.2)$ \\
\hline Difficulty in deciding on drug class & $106(67.5)$ \\
\hline Inability to decide on drug dose/strength & $105(66.9)$ \\
\hline $\begin{array}{l}\text { Inadequate theoretical knowledge of } \\
\text { therapeutic reasoning }\end{array}$ & $98(62.4)$ \\
\hline $\begin{array}{l}\text { Insufficient prescription writing sessions } \\
\text { per unit }\end{array}$ & $85(54.1)$ \\
\hline Difficulty in diagnosing the clinical case & $78(49.7)$ \\
\hline Difficulty in using the BNF & $59(37.6)$ \\
\hline $\begin{array}{l}\text { Inability to differentiate between generic and } \\
\text { brand drug names }\end{array}$ & $50(31.9)$ \\
\hline \multicolumn{2}{|l|}{ Open-ended responses } \\
\hline Need for more prescription writing sessions & $15(9.6)$ \\
\hline Lack of time during examination & $12(7.6)$ \\
\hline $\begin{array}{l}\text { Inability to decide on drug/drug dose/duration } \\
\text { of treatment according to BNF }\end{array}$ & $11(7.0)$ \\
\hline $\begin{array}{l}\text { Preference for smaller groups in prescription } \\
\text { writing sessions }\end{array}$ & $5(3.2)$ \\
\hline $\begin{array}{l}\text { Differences between questions in examinations } \\
\text { compared to prescription writing sessions }\end{array}$ & $4 \cdot(2.6)$ \\
\hline Lack of interest & $2(1.3)$ \\
\hline Unclear questions & $2(1.3)$ \\
\hline Difficulty of clinical cases & $2(1.3)$ \\
\hline $\begin{array}{l}\text { Lack of feedback on mistakes made in previous } \\
\text { examinations }\end{array}$ & $2(1.3)$ \\
\hline Lack of clarity on which topics to study & $2(1.3)$ \\
\hline $\begin{array}{l}\text { Lack of model answers discussed during } \\
\text { sessions }\end{array}$ & $2(1.3)$ \\
\hline
\end{tabular}

in the full study. The pilot questionnaire obtained a Cronbach's alpha value of 0.85 using the Statistical Package for the Social Sciences (SPSS), Version 19 (IBM Corp., Chicago, Illinois, USA). The validated questionnaire was then administered to all third- and fourth-year AGU medical students present in the class. Participating students filled in and returned the questionnaires anonymously.
Following their completion of the questionnaire, students were invited to participate in two focus group discussions according to academic year group. To ensure uniform representation, male and female medical students from each nationality present in the class were included. The discussions were led by a faculty member from the Department of Pharmacology \& Therapeutics at AGU who had not previously been involved in teaching or evaluating the students. During the discussions, the faculty member asked the students for comments on each of the 24 items of the questionnaire, in addition to any other comments, and recorded their responses in writing.

Data were compiled and analysed using Microsoft Excel, Version 2010 (Microsoft Corp., Redmond, Washington, USA). Qualitative data, including information collected from questionnaires and the focus group discussion, were thematically clustered and configured to a single specified unit of analysis.

This study was approved by the Research \& Ethics Committee of the College of Medicine \& Medical Sciences at AGU. Informed verbal consent was obtained from all participants following an explanation of the study's purpose and confirmation of the voluntary nature of participation.

\section{Results}

A total of 157 students participated in this questionnaire-based study; of these, 51 were male and 106 were female. A total of 82 students were in their third year and 75 were in their fourth year. All of the participants originated from Gulf Cooperation Council (GCC) countries. There was no significant difference in responses according to gender.

The students' closed- and open-ended responses regarding their poor performance in drug-related components of the OSPE are presented in Table 1. According to responses to closed-ended questions, the most frequently cited reasons for poor performance were an inability to correctly select the drugs (79.6\%), duration of treatment (69.4\%), quantity of drug to be dispensed (69.4\%) and drug formulation (68.2\%). Moreover, the majority of students stated that the time allowed for the completion of assigned tasks at the prescription writing OSPE stations was inadequate (68.8\%). The open-ended statements revealed that students also expected a greater number of training sessions, needed more information on correctly using the BNF and would prefer small group prescription writing sessions over large group sessions.

During the focus group feedback, 12 comments were given by students regarding reasons for their poor performance. Several of the comments confirmed 
Table 2: Reasons for absenteeism in prescription writing sessions according to preclerkship students at the Arabian Gulf University, Manama, Bahrain $(\mathrm{N}=157)$

\begin{tabular}{|c|c|}
\hline Reasons & n (\%) \\
\hline \multicolumn{2}{|l|}{ Closed-ended responses } \\
\hline Length of each session & $87(55.4)$ \\
\hline Lack of interest & $79(50.3)$ \\
\hline Reliance on peers to learn prescription writing & $76(48.4)$ \\
\hline Optional attendance policies & $74(47.1)$ \\
\hline Availability of prescription writing booklet & $67(42.7)$ \\
\hline $\begin{array}{l}\text { Reliance on medical professional relatives to } \\
\text { learn prescription writing }\end{array}$ & $66(42.0)$ \\
\hline $\begin{array}{l}\text { Prescription writing can be learnt after } \\
\text { graduation }\end{array}$ & $62(39.5)$ \\
\hline Lack of priority for studying* & $43(27.4)$ \\
\hline $\begin{array}{l}\text { Prescription writing is not important during the } \\
\text { preclerkship phase }\end{array}$ & $34(21.7)$ \\
\hline Sessions are not useful & $32(20.4)$ \\
\hline Peers have said that the sessions are not useful & $31(19.8)$ \\
\hline $\begin{array}{l}\text { Senior students have said that the sessions are } \\
\text { not useful }\end{array}$ & $26(16.6)$ \\
\hline \multicolumn{2}{|l|}{ Open-ended responses } \\
\hline Repetitive material & $9(5.7)$ \\
\hline Preference for smaller groups in sessions & $7(4.5)$ \\
\hline Lack of model answers provided & $7(4.5)$ \\
\hline Lack of interest & $6(3.8)$ \\
\hline Timing of sessions is not suitable & $6(3.8)$ \\
\hline Length of sessions & $5(3.2)$ \\
\hline $\begin{array}{l}\text { Lack of teaching focus on how to choose drugs } \\
\text { in sessions }\end{array}$ & $5(3.2)$ \\
\hline $\begin{array}{l}\text { Individual teaching style of the session } \\
\text { instructor }\end{array}$ & $3(1.9)$ \\
\hline $\begin{array}{l}\text { Differences between questions in examinations } \\
\text { compared to sessions }\end{array}$ & $3(1.9)$ \\
\hline $\begin{array}{l}\text { The prescription writing booklet is sufficient for } \\
\text { self-study }\end{array}$ & $2(1.3)$ \\
\hline
\end{tabular}

"Prescription writing comprises only 1-3 out of 30-35 of the objective structured practical examination stations.

similar views to those identified by the questionnaire responses. However, other comments revealed additional reasons for poor performance: stress and exhaustion due to the number of OSPE stations; the overall difficulty level of the OSPE; confusion regarding the duration of drug therapy; wasted time due to having to reopen the BNF at the second station; difficulty in utilising the printed rather than electronic version of the BNF to find drug information; and confusion as a result of other students' notes on the BNF, or after the BNF was left open by the previous student.

The students' closed- and open-ended responses regarding absenteeism from prescription writing sessions are presented in Table 2. The most cited reasons for absenteeism according to responses to the closed-ended questionnaire items were the length of each session (55.4\%), a lack of interest (50.3\%), reliance on peers to learn prescription writing (48.4\%) and optional attendance policies (47.1\%). Openended responses suggested that the repetitiveness of the material, focus on large-group instruction, lack of model examination answers provided, unsuitable timings of the sessions and the instructor's individual teaching style were also contributory to the students' absenteeism.

Comments made during the focus group discussion ( $\mathrm{n}=12$ each for third- and fourth-year students) supported these findings. Other reasons for student absenteeism included the proximity of the sessions to summative examinations; instruction on material which would not appear in the examination; emphasis on theoretical rather than practical skills in sessions; lack of focus in sessions on the drug selection process and the prescription; lack of usefulness of the sessions; and the limited priority given to the pharmacology OSPE stations.

\section{Discussion}

This descriptive study sought to identify possible reasons for poor performance in the drug-related components of prescription writing among AGU medical students. According to the responses, the majority of students expressed difficulty in various aspects of prescription writing, including choosing a particular drug from a class, identifying the appropriate dose and duration of treatment, calculating the quantity to be dispensed and deciding on the drug formulation to be used. These difficulties reflect insufficient clinical pharmacology knowledge about drugs and their use in treating various conditions. Medical students may be overwhelmed with the heavy course content as well as have difficulties remembering specific information, particularly drug names. Other reasons for poor performance identified in the present study included difficulty in using the BNF, a lack of time or stress when attempting to complete the examination and issues with the prescription writing sessions.

At AGU, students are trained either in groups or individually on how to use the BNF to seek relevant prescribing information. Nevertheless, in the authors' experience based on informal student feedback, some 
students do not practice using the BNF before their examination. Previous knowledge of which classes of drugs are appropriate for a particular clinical condition will enable the student to choose specific drugs from the BNF with relative ease. However, when individualising therapy, not all drugs within a class may be suitable. Avoiding these drugs requires an in-depth understanding of the mechanisms of their adverse effects and contraindications. This understanding is acquired through a deep learning approach and the ability to integrate learning with practical experience. ${ }^{1,2}$ Rather than memorising information, students therefore need to focus on understanding the basics of clinical pharmacology and applying these to individual patients. In order to minimise information overload, there should be greater emphasis on the personal drug (P-drug) concept, in line with the recommendations of the World Health Organization. ${ }^{13-15}$ Developing and maintaining a personal formulary has also been shown to increase student competence in rational prescribing. ${ }^{16}$ At AGU, medical students are encouraged to implement a personal formulary.

In the current study, many students reported that the time allocated for the prescription writing stations of the OSPE was insufficient to search for relevant information in the BNF and complete the task. At AGU, the time allocated for prescription writing stations is double that of the other stations (six versus three minutes). Nevertheless, this concern could be addressed by the provision in electronic format of the BNF or other relevant formulary, as this may reduce time needed during the OSPE station. In addition, students also revealed during the focus group discussion that they were stressed and exhausted during the OSPE as they had to complete more than 30 stations from various disciplines during a single examination. The stress and performance anxiety involved with summative examinations such as the OSPE could adversely affect decision-making abilities and the students' ability to use the BNF effectively. As such, perhaps prescription writing skills are best assessed in a continuous assessment format whereby each student is required to complete the task in a nonclassroom setting until a satisfactory result is achieved and certified by an instructor. During focus group sessions, several students felt that more prescription writing sessions were required. Some students suggested these sessions be conducted in a small group setting. While increasing the number of sessions and decreasing the student-to-teacher ratio per session would be desirable, both physical and faculty resources at AGU are limited and these suggestions may therefore not be feasible. Furthermore, it has been previously observed that some students do not attend the sessions already being held. ${ }^{12}$
Absenteeism from prescription writing sessions among participants in the current study was reported to be primarily due to the nature of the sessions and optional attendance policies. Approximately half of the respondents perceived the sessions to be too long or uninteresting. Additionally, several students indicated that the sessions were repetitive; however, in the opinion of the authors, reinforcement of previously covered material is important to enhance learning. Nearly half of the students reported that they did not attend the sessions because of optional attendance policies. As the PBL curriculum at AGU involves a student-centred self-study approach, attendance is optional across the curriculum for certain educational activities. However, attendance at prescription writing sessions has been shown to be an important determinant of performance and the acquisition of rational therapeutic decision-making and prescription writing skills. ${ }^{12}$ Certain participants in the current study seemed to follow an examinationoriented approach, with some students commenting during the focus group discussion on the inadequate timing of the sessions in relation to the examinations. Furthermore, some students noted in open-ended responses that cases discussed in the sessions did not appear in the examination; however, it is important to note that the OSPE tests students on the same concepts as those covered in the sessions, although the clinical scenarios differ. Studying the same cases as those provided in the examination would only encourage rote learning. Previous research has found that medical students who do not learn the basic concepts and principles of prescription writing find it difficult to apply their knowledge in similar situations, known as the transfer effect. ${ }^{17}$ It is likely that this problem is further compounded when students do not attend interactive prescription writing sessions.

The results of this study suggest that changes should be made to the prescription writing sessions at AGU to ensure that the classes are held more frequently, are more interesting and that the material is delivered in smaller groups and in a vertically integrated manner during the subsequent clinical clerkship training in phase III of the medical programme. However, the authors of the current study also recommend that AGU medical students should be encouraged to improve their approach to learningmoving from examination-oriented strategies to those that will facilitate the understanding of fundamental concepts and their application to different therapeutic scenarios. Although this was not investigated in the current study, another possible reason for lack of attendance at prescription writing sessions may have been due to a mistaken belief among the students that passing each OSPE station is not necessary 
because their final grade is based on an aggregate score. In reality, final grades are based on multiple assessments that involve knowledge, skills and attitude components derived from written examinations, the OSPE, objective structured clinical examinations and on-going evaluation of student performance in small-group tutorials. Further research is needed to determine whether this mistaken belief influences absenteeism; if so, there is a need to revisit assessment policies in a broader context to address such concerns without compromising integration, a central aspect of problem-based learning (PBL).

In an editorial, Kanter critiqued the reasons for student absenteeism, including generational and technological issues, values and etiquette. ${ }^{18}$ In his view, issues of absenteeism arise due to factors involving the learner-teacher relationship, rather than problems of attendance. Hence, a key priority in combatting absenteeism is to investigate factors which drive student engagement within the learnerteacher relationship. Focusing on the learner-teacher relationship may therefore "broaden the discussion to learners at all levels and to all forms of the learnerteacher relationship, including advising and mentoring sessions". ${ }^{18}$ Further research has also confirmed that solutions for student absenteeism should take into account the learner-teacher relationship. ${ }^{19,20}$ The findings of the current study should therefore be interpreted in this broader perspective in order to find solutions for student absenteeism and to enhance learning.

Although student absenteeism in classroom activities is a universal problem, the generalisability of the current findings may be somewhat limited. Enforcement of attendance policies may differ across various institutions. However, one of the tenets on which PBL relies is the adult learning principle, which necessitates that the learner is motivated enough to realise that certain professional skills require the supervision of a mentor rather than solely self-regulated learning. As an increasing number of healthcare programmes in the GCC region are considering implementing curriculum innovations, the insights provided by this study may inform policy decisions regarding student attendance as well as determine the most appropriate stage in the undergraduate medical curriculum to introduce drug prescribing skills. ${ }^{21-24}$

\section{Conclusion}

The results of this study suggest that AGU medical students performed poorly in the drug-related components of prescription writing due to inadequate clinical pharmacology knowledge. Lack of participation in interactive prescription writing sessions was attributed to optional attendance policies and because students felt that the sessions were too long and uninteresting. Based on these findings, efforts are recommended to improve student participation, learning and performance at prescription writing sessions. Greater emphasis should be placed on the P-drug concept and the development of a personal formulary. In addition, absenteeism should be considered in the context of the learner-teacher relationship.

\section{ACKNOWLEDGEMENTS}

The authors are grateful to the AGU medical students for their participation in this study.

\section{CONFLICT OF INTEREST}

The authors declare no conflicts of interest.

\section{References}

1. Maxwell S, Walley T; BPS Clinical Section Committee. Teaching safe and effective prescribing in UK medical schools: A core curriculum for tomorrow's doctors. Br J Clin Pharmacol 2003; 55:496-503. doi: 10.1046/j.1365-2125.2003.01878.x.

2. Richir MC, Tichelaar J, Geijteman EC, de Vries TP. Teaching clinical pharmacology and therapeutics with an emphasis on the therapeutic reasoning of undergraduate medical students. Eur J Clin Pharmacol 2008; 64:217-24. doi: 10.1007/s00228007-0432-z.

3. Dornan T, Ashcroft D, Heathfield H, Lewis P, Miles J, Taylor D, et al. An in depth investigation into causes of prescribing errors by foundation trainees in relation to their medical education: EQUIP study. From: www.gmc-uk.org/FINAL_Report_prev alence_and_causes_of_prescribing_errors.pdf_28935150.pdf Accessed: Dec 2015.

4. Al Khaja KA, Sequeira RP, Al-Ansari TM, Damanhori AH. Prescription writing skills of residents in a family practice residency programme in Bahrain. Postgrad Med J 2008; 84:198-204. doi: 10.1136/pgmj.2007.062547.

5. Al Khaja KA, Handu SS, James H, Mathur VS, Sequeira RP. Assessing prescription writing skills of pre-clerkship medical students in a problem-based learning curriculum. Int J Clin Pharmacol Ther 2005; 43:429-35. doi: 10.5414/CPP43429.

6. General Medical Council. Tomorrow's doctors: Outcomes and standards for undergraduate medical education. From: www. gmc-uk.org/Tomorrow_s_Doctors_1214.pdf_48905759.pdf Accessed: Dec 2015.

7. Sequeira RP. Patient safety in medical education: Medication safety perspectives. Indian J Pharmacol 2015; 47:135-6. doi: 10. 4103/0253-7613.153417.

8. Lofholm PW, Katzung BG. Rational prescribing and prescription writing. In: Katzung BG, Masters SB, Trevor AJ, Eds. Basic and Clinical Pharmacology. 12th ed. New York, USA: McGraw-Hill Medical, 2012. Pp. 1139-48.

9. James H, Al Khaja KA, Sequeira RP. Effective use of real-life events as tools for teaching-learning clinical pharmacology in a problem-based learning curriculum. Indian J Pharmacol 2015; 47:316-21. doi: 10.4103/0253-7613.157131. 
10. Richir MC, Tichelaar J, Stanm F, Thijs A, Danner SA, Schneider AJ, et al. A context-learning pharmacotherapy program for preclinical medical students leads to more rational drug prescribing during their clinical clerkship in internal medicine. Clin Pharmacol Ther 2008; 84:513-16. doi: 10.1038/ clpt.2008.82.

11. British National Formulary. BNF publications. From: www.bnf. org/ Accessed: Dec 2015.

12. Al Khaja KA, James $H$, Sequeira RP. Effectiveness of an educational intervention on prescription writing skill of preclerkship medical students in a problem-based learning curriculum. J Clin Pharmacol 2013; 53:483-90. doi: 10.1002/ jcph.68.

13. de Vries TP, Henning RH, Hogerzeil HV, Fresle DA; World Health Organization Action Programme on Essential Drugs. Guide to good prescribing: A practical manual. From: http://apps.who.int/medicinedocs/pdf/whozip23e/whozip23e. pdf Accessed: Dec 2015.

14. Khan AA, Bagewadi HG. Medical students' task based learning of P-drug concept: A study to know its effectiveness and participant feedback. Int J Pharmacol Res 2015; 5:8-11. doi: 10.7439/ijpr.v5i1.1418.

15. Keijsers CJ, Segers WS, de Wildt DJ, Brouwers JR, Keijsers L, Jansen PA. Implementation of the WHO-6-step method in the medical curriculum to improve pharmacology knowledge and pharmacotherapy skills. Br J Clin Pharmacol 2015; 79:896-906. doi: $10.1111 /$ bcp. 12575 .

16. De Vries TP, Daniels JM, Mulder CW, Groot OA, Wewerinke L, Barnes KI, et al. Should medical students learn to develop a personal formulary? An international, multicentre, randomised controlled study. Eur J Clin Pharmacol 2008; 64:641-6. doi: $10.1007 / \mathrm{s} 00228-008-0465-y$.
17. De Vries TP. Presenting clinical pharmacology and therapeutics: Evaluation of a problem based approach for choosing drug treatments. Br J Clin Pharmacol 1993; 35:591-7. doi: 10.1111/ j.1365-2125.1993.tb04187.x.

18. Kanter SL. To be there or not to be there: Is attendance really the question? Acad Med 2012; 87:679. doi: 10.1097/ACM. 0b013e31825a5a2a.

19. Cornelius-White J. Learner-centered teacher-student relationships are effective: A meta-analysis. Rev Educ Res 2007; 77:113-43. doi: 10.3102/003465430298563.

20. Bin Abdulrahman KA. Students' views on student-teacher relationship: A questionnaire-based study. J Family Community Med 2007; 14:81-7.

21. World Federation for Medical Education. WFME global standards for quality improvement: The 2015 revision. From: http://wfme.org/standards/bme/78-new-version-2012-quality -improvement-in-basic-medical-education-english/file Accessed: Dec 2015.

22. Al-Muhanna FA, Subbaroa VV. Standards in medical education and GCC countries. J Family Community Med 2003; 10:15-17.

23. Yudkowsky R, Park YS, Lineberry M, Knox A, Ritter EM. Setting mastery learning standards. Acad Med 2015; 90:1495-500. doi: 10.1097/ACM.0000000000000887.

24. Dreyfus SE. The five-stage model of adult skill acquisition. Bull Sci Technol Soc 2004; 24:177. doi: 10.1177/0270467604264992. 